\title{
The use of administrative data for measuring medical outcome - perspectives
}

Output-oriented medical payment systems for hospitals, usually based on different versions of diagnosis related groups (DRGs), have become common in most industrialized countries. These systems require the documentation of the principal diagnosis, comorbidities and procedures besides basic demographic information. Due to the implications for payment, the medical data is well controlled within the hospital as well as by payors (i.e. insurance companies) and thus is quite reliable. Furthermore it is available not only inside the hospitals but also to payors. Using logical (boolean) combinations of diagnoses, procedures and demographic information any indicator that can be defined in this way can be derived from these data. The method is limited by the level of detail provided by the coding systems for diagnoses and procedures. However, these limitations are not of principal nature because coding systems may be changed to cover necessary details for quality measurement.

\section{Using medical indicators based on hospital data \\ $\nabla$}

In Germany the Helios hospital group has used administrative data for quality management since 2000. More than 700 medical indicators are derived from the data set and distributed monthly within all 38 acute care hospitals to the chairman of the departments as well as to administrators and CEOs. The indicators cover the most frequent as well as the most important diseases and procedures. Information is given for frequencies, outcome indicators (like mortality or the occurrence of certain complications), the practical use of certain procedures and other combined items. For many of the outcome indicators goals have been defined. For 30 important diseases and/or procedures outcome indicators are made publicly available (i.e. AMI mortality, mortality from mechanical ventilation, mortality from colorectal procedures, use of laparoscopic methods etc.).

For departments which don't reach their goals a structured audit process (peer review) has been set up. Chairmen of other departments will look into treatment processes using the medical records of selected critical cases and try to identify weaknesses and medical errors in order to identify opportunities for improving the treatment process. These measures have lead to measurable improvements within the hospital group. Relative changes of a $5 \%$ to $30 \%$ decrease of mortality have been achieved. In most areas the indica- tors for the group have become significantly better than the risk adjusted national average. The medical indicators may not only be used for such quality improvement, but also for economic SWOT analyses of a hospital.

\section{Using long term indicators based on insurance data $\nabla$}

Based on these experiences the largest German sickness fund (AOK), the FEISA institute for social medicine in Magdeburg and the Helios group have developed a new method for the analysis of payor data. Insurance companies in Germany gather information about all inpatient and outpatient acute care events of the insured population. By linking the treatment chains via pseudonymous patient identifications any major medical event following a certain preceding medical starter event may be identified. A starter event (also called tracer event) could for example be an acute myocardial infarction. Follow up indicators may be mortality rates (30-days, 90-days etc.), the use of left heart catheterization vs. open heart surgery, general and specific readmission rates (i.e. admission for re-catheterisation) and many more. Thus long term outcome can be measured using readily available data. Meanwhile the first reports covering eight tracer events are available to all German hospitals.

This new method provides standardized information about long term outcome which can now easily be extended to more tracer events. By it's nature the method is comparatively resistant to possible manipulations by providers of the tracer event. It can be used for comparing providers, regions and even national health systems. Furthermore the spread of new medical methods within a country and their outcome under practical conditions can be investigated. This may complement (not replace) scientific studies.

\section{Résumé \\ $\nabla$}

New methods of measuring medical indicators from administrative data can improve hospital management as well as medical outcome. The application of this technique to long term treatment data of insurance companies or national health systems can yield valuable information about hospital as well as health system performance, which has not been available on such a wide scale before.

Autorenerklärung: Der Autor ist bei den HELIOS Kliniken für das Qualitätsmanagement zuständig.
T. Mansky

Qualitätsmanagement

Key words

outcome indicators

administrative data

$\checkmark$ audit

quality improvement

Schlüsselwörter

Qualitätssicherung

Qualitätsmanagement

Audit

Routinedaten

Institut

HELIOS Kliniken GmbH Berlin

Bibliografie

DOI 10.1055/s-0028-1085582

Dtsch Med Wochenschr 2008; 133: S 135 - (c) Georg Thieme Verlag KG Stuttgart - New York . ISSN 0012-0472

Korrespondenz

PD Dr. Thomas Mansky

Abteilungsleiter Medizinische Entwicklung

HELIOS Kliniken GmbH

Friedrichstr. 136

10117 Berlin

Tel. +49 (30) 531 321-140

eMail thomas.mansky@

helios-kliniken.de 